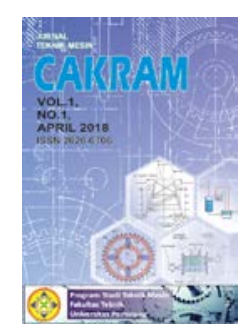

\title{
DESAIN GEOMETRI IKATAN PENGUNCI MEKANIS ANTAR SPARE PART PADA PRODUK VALEX FOLIFIX
}

\author{
Catur Kurniawan $^{1}$ \\ ${ }^{1}$ Program Studi Teknik Mesin, Universitas Pamulang, Jl. Surya Kencana No.1, Tangerang Selatan, Indonesia \\ E-mail :dosen00578@unpam.ac.id
}

Masuk : 12 Februari 2020

Direvisi : 4 Maret 2020

Disetujui : 13 Maret 2020

\begin{abstract}
Abstrak: Paper ini memberi pendekatan ilmiah bahwa desain geometri ikatan pengunci mekanis antar spare part pada produk Valex Folifix telah memenuhi unsur layak untuk diproduksi massal. Masalah krusial pada paper ini terletak pada proses assembly antar part ekstrusi. Disyaratkan dalam membentuk suatu produk kap lampu listrik haruslah dimampukan oleh tenaga operator secara manual dengan waktu yang singkat sekaligus tanpa merusak struktur materialnya. Melalui studi eksperimental iterasi optimasi geometri optimal Finite Element Methode (FEM) diperoleh hasil bahwa profil kunci sendi bulat pada suatu lempengan spare part akan memasuki celah menganga kontur sendi sangkar pada lempengan spare part lainnya dengan mengikuti suatu pola travelling tertentu pada arah gaya radial dan circumferensial sebesar $18.5 \mathrm{~kg}$. Profil sejarak arah longitudinal $1 \mathrm{~cm}$ ini saling menekan satu sama lain. Gaya tekan ini akan memperlebar bukaan menganga sendi sangkar maksimal sejarak $0.15 \mathrm{~mm}$ dari posisi awalnya dan dapat melewatkan sendi bulat masuk sempurna ke dalam sendi sangkar. Hasil-hasil di atas memenuhi syarat luminaire (yaitu syarat kekokohan mekanis suatu kap lampu listrik).
\end{abstract}

Kata kunci: Luminaire, sendi bulat, sendi sangkar, FEM

Abstract: This paper provides a scientific approach that the geometrical design of mechanical locking valence between spare parts in Valex Folifix products has fulfilled elements suitable for mass production. The crucial problem in this paper lies in the assembly process between the extrusion parts. Required in forming an electric lighting fixtures product must be enabled by operator personnel manually with a short time at once without damaging the material structure. Through an experimental study of optimal geometry optimization iteration Finite Element Method (FEM) results show that the key profile of a round joint on a spare part plate will enter the gaping gap of the contour joint on another spare part plate by following a certain traveling pattern in the direction of radial and circumferential forces of $18.5 \mathrm{~kg}$. These longitudinal $1 \mathrm{~cm}$ long distance profiles are pressed against one another. This compressive force will widen the gaping opening of the cage joint a maximum of $0.15 \mathrm{~mm}$ from its initial position and can pass the round joint into the cage joint perfectly. The above results meet the luminaire requirements (ie the mechanical robustness requirements of an electrical lighting fixtures).

Keywords: Luminaire, round joints, cage joints, FEM

\section{PENDAHULUAN}

Valence material extrusion for lighting fixtures disingkat Valex Folifix memiliki lima buah spare part. Bentuk dasar setiap part berupa lempengan yang dibubuhi alur-alur pengunci. Pengunci sendi bulat pada suatu 
part akan berikatan dengan kunci sendi sangkar pada spare part lainnya ${ }^{[2]}$. Paper ini mengungkap desain geometri sendi bulat dan sendi sangkar agar dicapai kemudahan memasang kunci dan jaminan kekuatan ikatannya. Valensi atau titik sendi ikatan ini seperti poros yang dapat memberi kebebasan sudut beberapa derajat antar lempengan spare part yang saling berikatan tersebut. Perolehan sudut yang dibentuk dari dua bilah spare part hasil ekstrusi ini dapat mensubstitusi hasil perolehan proses bending pada arah longitudinal. Persambungan secara kontinyu disediakan oleh sistem ini menggabungkan beberapa spare part membentuk kontur yang diinginkan. Sedangkan pada arah transversal penghujung arah longitudinal dari sparepart yang menyediakan kunci sangkar dapat menerima baut berulir sebagai sistem ikatan tepi benda kerja pada lempengan yang bertugas menutup tepian. Sistem ikatan baut pada sendi kunci mensubstitusi hasil perolehan proses spot welding.

Sendi bulat harus mendapat sedikit ceruk di bagian depan yang mengurangi luasan diameternya hingga terdapat kontur yang lebih runcing. Kontur runcing ini berfungsi sebagai bidang miring ${ }^{[6]}$ pengungkit yang dapat diterima rahang sendi sangkar. Secara umum semua kontur harus bergeometri streamline yang mulus sesuai kaidah ekstrusi $^{[8]}$. Demikian juga, ia harus memiliki sejumlah persyaratan lainnya seperti ketebalan badan minimum, bukaan kolom rahang minimum, diameter minimum ${ }^{[8]}$. Tentu saja harus disadari bahwa penggunaan jumlah kubikasi material berbanding lurus dengan biayanya secara ekonomis ${ }^{[4][5]}$.

Tujuan utama paper ini ada dua. Pertama, membuat desain geometri sendi bulat agar mudah masuk ke dalam sendi sangkar di posisi DoF release. DoF (Degree of Freedom) adalah derajat kebebasan bukaan rahang. Ke dua, membuat desain geometri sendi sangkar agar mampu menahan sendi bulat yang telah terpasang tetap terkunci di posisi DoF lock. Desain geometri sendi dirancang dengan tetap memperhatikan pemenuhan batasan azas manufacturabiility extrusion, batasan azas luminaire, batasan azas hand manual assembly, dan batasan azas non destructive material part.

Valex Folifix adalah merek dagang terdaftar di kemenkumhan RI sebagai produk dengan paten berbasis inovasi teknologi produksi ${ }^{[3]}$ di bidang kap perlampulistrikan yang sudah dikenal masyarakat ${ }^{[1]}$. Syarat kekokohan ikatan ini penting sebagai syarat perlu untuk mencapai kekuatan kap lampu sebagaimana yang dipersyaratkan SNI dalam bidang luminaire ${ }^{[7]}$. Material yang digunakan adalah Aluminium Alloy seri 6063 yang memiliki property sebagaimana tabel pada bagian $5 b .1^{[9]}$.

Sebelumnya, kap lampu TL Flurescence dan TL LED dibuat dari bahan pelat baja tipis 0.3 sampai 0.7 mm. Teknologi yang digunakan adalah work sheet metal process fabrication dengan urutan proses shear, drill, pounch, bend, weld, painting.

\section{METODOLOGI}

Paper ini menerapkan metodologi eksperimental iterasi optimasi geometri optimal Finite Element Methode dengan tools SolidWork. Prosedur yang digunakan:

2.1 Membedah gambar bukaan penampang transversal yang menunjukkan anatomi kunci sendi bulat dan kunci sendi sangkar

2.2 Membuat route travelling sendi bulat memasuki sendi sangkar

2.3 Mendapatkan posisi bukaan maksimal sendi sangkar

2.4 Mendapatkan kepastian posisi locking sempurna setelah sendi bulat masuk ke sendi sangkar

2.5 Mensimulasikan menggunakan simulator SolidWork dengan tahapan

2.5.1 Membentuk sketsa dan Feature profil

2.5.2 Menyesuaikan data entry properties material

2.5.3 Menetapkan Fix Geometri pada penampang yang dipilih sesuai keadaan

2.5.4 Menetapkan besaran gaya yang dikenakan pada bidang

2.5.5 Melakukan proses meshing

2.5.6 Melakukan proses running simulation

2.5.7 Mendapatkan hasil.

2.6 Menganilisis hasilnya dan melakukan suatu kajian apakah memenuhi batasan azas manufacturabiility extrusion, batasan azas luminaire, batasan azas hand manual assembly, dan batasan azas non destructive material part. 


\section{HASIL DAN PEMBAHASAN}

Sebagaimana alur yang disebutkan pada bagian Metodologi diatas, diperoleh hasil-hasil sebagai berikut: 3.1 Membedah gambar bukaan penampang transversal yang menunjukkan anatomi kunci sendi bulat dan kunci sendi sangkar

Nampak suatu cerukan pada bulatan sendi ikat bulat dan nampak sendi sangkar yang menganga siap menerima sendi ikat bulat. Anotasi ukuran tidak disebutkan mengingat dalam perlindungan paten. Namun secara umum dapat disebutkan untuk alasan kemampu-ekstrusian (manufacturability), maka batasan ketebalan bahan $0.8 \mathrm{~mm}$ dan diameter dalam sendi sangkar $2 \mathrm{~mm}$ dengan bukaan celah sendi sangkar menganga sebesar minimum $1.5 \mathrm{~mm}$. Seluruh rusuk diberi kontur fillet yang cukup sebagaimana ditunjukkan dalam gambar 1 .

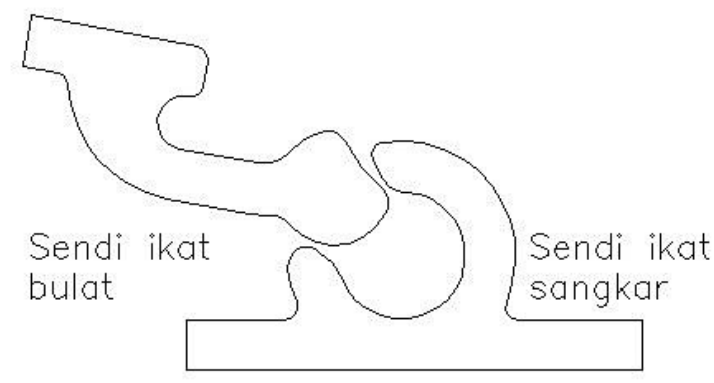

Gambar 1. Bentuk geometri umum sendi ikat bulat dan sendi ikat sangkar

3.2 Membuat route travelling sendi bulat memasuki sendi sangkar

Gambar 2 di bawah ini adalah potongan transversal dari suatu ekstrusi dimana tahap demi tahap sendi ikat bulat memasuki sendi ikat sangkar.

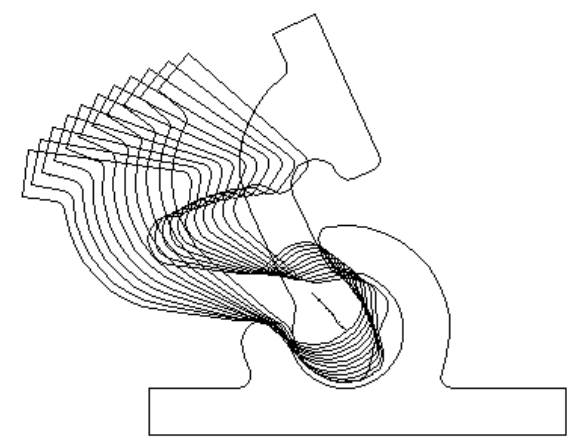

Gambar 2. Route traveling sendi bulat memasuki sendi sangkar

3.3 Mendapatkan posisi bukaan maksimal sendi sangkar

Dalam hal ini dipilih suatu tahapan dari traveling sebagaimana ditunjukkan pada gambar 2 di atas dapat diperoleh sejarak 0.15 mm sebagaimana ditunjukkan dalam gambar 3.

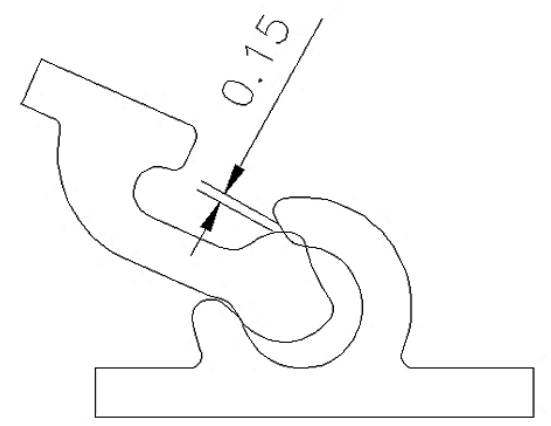

Gambar 3. Posisi bukaan maksimal sendi sangkar 
3.4 Mendapatkan kepastian posisi locking sempurna

Posisi locking sempurna diperoleh setelah sendi bulat masuk ke sendi sangkar. Pada posisi ini kedua sendi telah berikatan sempurna dan menyerupai sebuah ikatan engel (hinge). Kebebasan gerak engel antar part yang berpasangan pada teknologi hasil ekstrusi ini dapat membentuk suatu kontur sudut yang diperlukan bagi desain suatu kap lampu untuk meniru capaian kontur seperti hasil proses bending pada teknologi work sheet metal. Capaian posisi ini minimal harus dimampukan pada prosas hand manual assembly, yaitu dengan kekuatan tenaga tangan manusia dapat merakitnya tanpa terjadi suatu destruksi pada material spare partnya sebagaimana ditunjukkan dalam gambar 4.

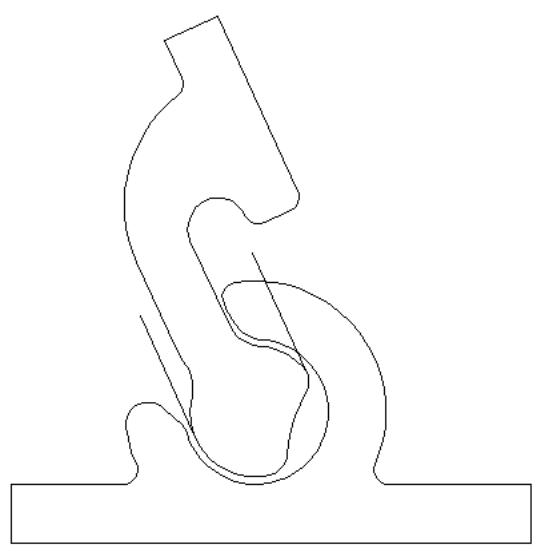

Gambar 4. Posisi locking sempurna berperilaku seperti engsel

3.5 Menganalisis menggunakan simulator SolidWork

3.5.1 Melakukan setting Feature profil ekstrusi

Sendi bulat diambil sampel $10 \mathrm{~mm}$ arah longitudinal sebagaimana ditunjukkan dalam gambar 5a.

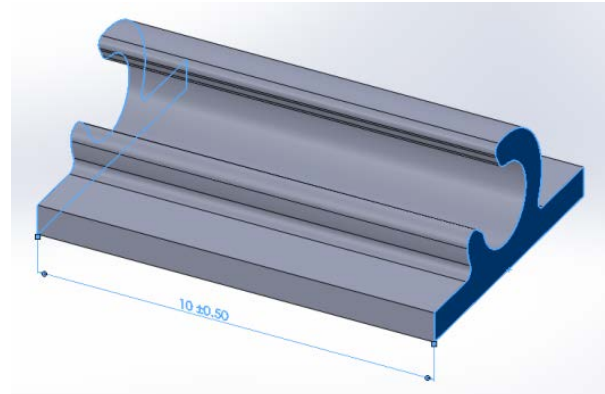

Gambar 5a. Sendi sangkar dalam arah ekstrusi longitudinal

\subsubsection{Menyesuaikan data entry properties material}

Data entry properties material pada simulator disetting sesuai dengan fisik material sesungguhnya. Yaitu material aluminium rod extrusion seri 6063 sebagaimana ditunjukkan dalam Tabel 5b.1 dan Gambar 5b.2.

Tabel 5b.1 Property Material 6063-O, Extruded Rod (SS) 
Jurnal Teknik Mesin: CAKRAM 2020

Catur Kurniawan, Desain Geometri Ikatan Pengunci Mekanis Antar Spare Part pada Produk Valex Folifix

\begin{tabular}{|l|l|l|}
\hline Property & Value & Units \\
\hline Elastic Modulus in X & 703599.91 & $\mathrm{kgf} / \mathrm{cm}^{\wedge} 2$ \\
\hline Poisson's Ration in $\mathrm{XY}$ & 0.33 & $\mathrm{~N} / \mathrm{A}$ \\
\hline Shear Modulus in $\mathrm{XY}$ & 263085.18 & $\mathrm{~kg} / \mathrm{cm}{ }^{\wedge} 2$ \\
\hline Mass Density & 0.0027 & $\mathrm{~kg} / \mathrm{cm}^{\wedge} 3$ \\
\hline Tensile Strength in X & 917.74 & $\mathrm{kgf} / \mathrm{cm}^{\wedge} 2$ \\
\hline Compressive Strength in X & & $\mathrm{kg} / \mathrm{cm}^{\wedge} 2$ \\
\hline Yield Strength & 421.84 & $\mathrm{kgf} / \mathrm{cm}^{\wedge} 2$ \\
\hline Thermal Expansion Coefficient in X & $2.3 \mathrm{e}-005$ & $\Gamma{ }^{\circ} \mathrm{C}$ \\
\hline Thermal Conductivity in X & 0.521033 & $\mathrm{caV}\left(\mathrm{cm} \cdot \mathrm{sec} \cdot{ }^{\circ} \mathrm{C}\right)$ \\
\hline Specific Heat & 215.105 & $\mathrm{caV}\left(\mathrm{kg} \cdot{ }^{\circ} \mathrm{C}\right)$ \\
\hline Material Damninn Ratin & & $\mathrm{N} / \mathrm{A}$ \\
\hline
\end{tabular}

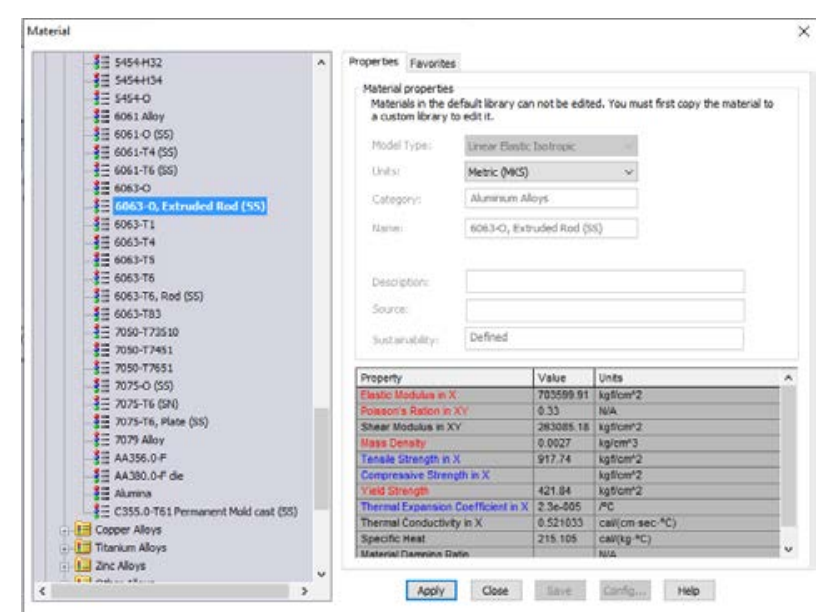

Gambar 5b.2 Kotak dialog piranti lunak SolidWork untuk menentikan sifat material Aluminium rod extrusion seri 6063

3.5.3 Menetapkan setting Fix Geometri

Fix Geometri pada penampang yang dipilih sesuai keadaan dimana part dipegang dengan kokoh sebagaimana ditunjukkan dalam gambar 5c.

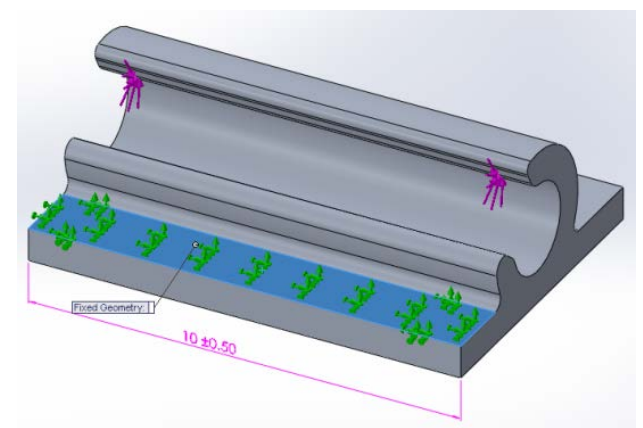

Gambar 5c. Simulasi fix geometri sesuai keadaan dimana part dipegang dengan kokoh

3.5.4 Menetapkan besaran gaya yang dikenakan pada bidang

Dalam hal ini, saat sendi bulat travelling memasuki celah sendi sangkar, ia akan mendesak bagian langitlangit sendi sangkar ke atas sejauh $0.15 \mathrm{~mm}$. Dipilih suatu nilai tamu besaran gaya sebesar $21 \mathrm{~kg}$. Sesuai konturnya, maka gaya bekerja pada arah radial dan circumferensial sebagaimana ditunjukkan dalam gambar $5 \mathrm{~d}$. 


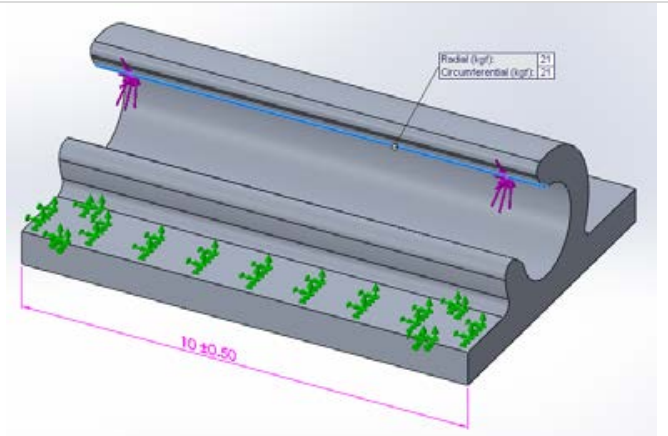

Gambar 5d. Gaya yang bekerja pada arah radial dan circumferensial

\subsubsection{Melakukan proses meshing}

Proses meshing disetting pada rentang yang cukup sekitar 75\% bagian antara meashing coarse - fine dengan maksud mendapatkan hasil akurasi yang baik sebagaimana ditunjukkan dalam gambar 5e.

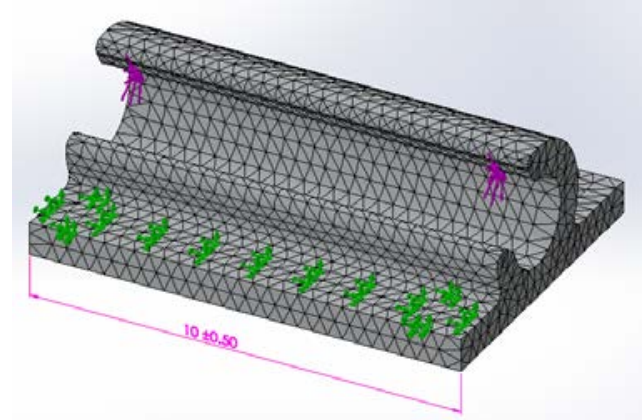

Gambar 5e. proses meshing,membagi objek menjadi bagian kecil yang sederhana

\subsubsection{Melakukan proses running simulation}

Proses running simulation dilakukan dengan menggunakan nilai tamu besaran gaya sebesar $21 \mathrm{~kg}$. Sebagaimana disebutkan di dalam poin 5.d. Diperoleh pergeseran lokasi sejarak $0.17 \mathrm{~mm}$ dari posisi awalnya sebagaimana ditunjukkan dalam gambar $5 f$.

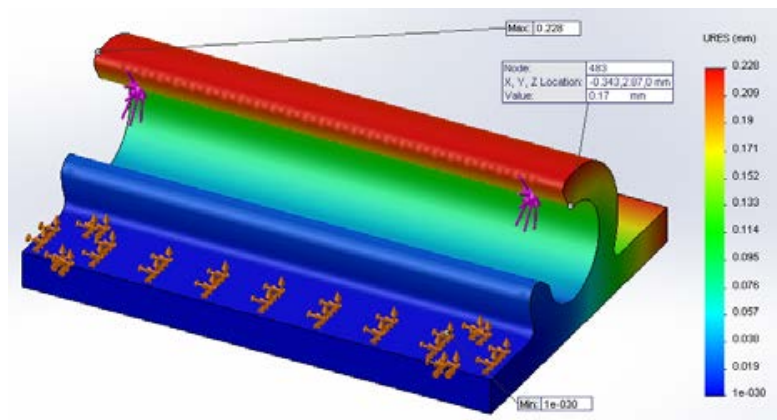

Gambar 5f. Hasil study awal dengan suatu nilai tamu

\subsubsection{Melakukan iterasi lanjutan}

Iterasi lanjutan dilakukan untuk mengetahui kisaran gaya yang diperlukan dengan mengubah sedikit nilai tamu dengan nilai iterasi ke 1 sampai ke-n. Diperoleh nilai optimal gaya yang diberikan 18.5 kg agar diperoleh pergeseran lokasi sejarak $0.15 \mathrm{~mm}$ dari posisi awalnya.

\subsection{Pembahasan hasil eksperimen}

Sebagai pembahasan hasil eksperimen di atas bahwa profil kunci sendi bulat akan memasuki celah menganga kontur sendi sangkar mengikuti pola travelling tertentu dengan arah gaya radial dan circumferensial. Profil sejarak arah longitudinal $1 \mathrm{~cm}$ ini saling menekan satu sama lain. Gaya tekan ini 
akan memperlebar bukaan menganga dari posisi awalnya dan dapat melewatkan sendi bulat masuk sempurna ke dalam sendi sangkar. Beberapa batasan terpenuhi sekaligus:

3.6.1 Batasan azas manufacturability extrusion

Azas manufacturability extrusion dipenuhi pada pembahasan di pasal 3.1 diatas, dimana desain geometri dirancang menggunakan ketebalan umum lempengan ekstrusi $0.8 \mathrm{~mm}$ dengan bukaan celah $1.5 \mathrm{~mm}$ dan diameter sendi sangkar $2 \mathrm{~mm}$.

3.6.2 Batasan azas luminaire

Azas lumainaire yaitu kelayakan sebagai produk kap lampu yang mampu mengikuti bentuk kontur kap lampu dipenuhi pada pasal 3.4 di atas, dimana setelah berpasangan sempurna, perilaku ikatan akan seperti engsel yang memungkinkan membentuk suatu derajat kebebasan sudut untuk meniru tekukan pola kontur kap lampu yang kokoh.

3.6.3 Batasan azas hand manual assembly

Azas hand manual assembly yaitu gaya sebesar yang disarankan masih mampu dihasilkan secara mudah oleh tangan manusia dipenuhi pada pasal 3.5.1 sampai 3.5.7 di atas dalam arah radial dan circumferensial sebesar $18.5 \mathrm{~kg}$ saja. Dimana gaya hanya diberikan kurang dari satu detik pada spare part. Ini menjadikan usaha yang ringan. Panjang longitudinal sejauh $1 \mathrm{~cm}$ cukup memudahkan operator memasangkan dua bilah spare part.

3.6.4 Batasan azas non destructive

Azas non destructive pada proses pemasangan tanpa mendeformasi plastis struktur geometrinya dipenuhi pada pasal 3.5.7. dimana sendi sangkar hanya terkoreksi elastis sebesar $0.15 \mathrm{~mm}$ dengan gaya $18.5 \mathrm{~kg}$. Gaya dan deformasi ini masih jauh dibawah batas yield strength sebagaimana disebutkan di tabel 5.b1

\section{KESIMPULAN}

Eksperimen menggunakan simulasi sangat diperlukan dalam proses pengembangan produk. Hal ini diperlukan sebagai laboratorium yang murah sebelum suatu desain diproduksi. Terlebih lagi bila keperluannya untuk diproduksi massal. Paper ini memberi klaim ilmiah melalui metode Finite element dengan simulasi piranti lunak SolidWork bahwa Desain geometri ikatan pengunci mekanis antar spare part pada produk Valex Folifix telah memenuhi unsur untuk diproduksi massal dimana batasan manufacturabiility extrusion, batasan luminaire, batasan non destructive dan batasan hand manual assembly keseluruhannya secara memuaskan dapat dipenuhi.

Pada paper lanjutan akan dibahas kekuatan struktur menahan gaya tarik setelah dua bilah part yang masing-masing memiliki kunci sendi bulat dan kunci sendi sangkar berpasangan serta perluasan analisis perilaku kekuatan ikatan engselnya pada derajat-derajat kebebasan yang dimungkinkan. Kemudian akan dibahas juga pola traveling dan posisi rotasi antar spare part valex folifix sebagai jalur pandu penjejakan mekanis sarana perakitan secara otomatis di industri 4.0.

\section{DAFTAR PUSTAKA}

[1]. APERLINDO, Majalah SENTRA ELEKTRIK, Hal. 48 No.8 Tahun XVIII / Nopember 2018

[2]. Catur Kurniawan, Paten P00201800147,Kemenkumham RI, 2018

[3]. Catur Kurniawan, "Valex Folifix”, Dokumen Tenant INBISTEK, BIT-TBIC-PUSPIPTEK, 2017-2018

[4]. Lincolin Arsyad, Ekonomi Industri, ISBN 9789790119949, Tangerang Selatan: Universitas Terbuka, 2015.

[5]. Materialprices.com, (2012), Accessed May 15th.2012

[6]. Robert G. Brown, Introductory Physics I Elementary Mechanics, Duke University Physics Department Durham, NC 27708-0305,rgb@phy.duke.edu, 2013

[7]. SNI 04-6973.2.1:2015 Luminaire, Standar Nasional Indonesia, Kemenkumham RI, 2015

[8]. Yogesh Dewang, A study on metal extrusion process, International Journal of LNCT, Vol 2(6) ISSN (Online): 2456-9895, 2018 